Article

\title{
Antimicrobial Properties of Diamond-Like Carbon/Silver Nanocomposite Thin Films Deposited on Textiles: Towards Smart Bandages
}

\author{
Tadas Juknius ${ }^{1}$, Modestas Ružauskas ${ }^{2}$, Tomas Tamulevičius ${ }^{1,3}$, , Rita Šiugždinienè ${ }^{2}$, \\ Indrè Juknienè $^{2}$, Andrius Vasiliauskas ${ }^{2}$, Aušrinè Jurkevičiūtè ${ }^{1}$ and Sigitas Tamulevičius ${ }^{1,3}$ \\ 1 Institute of Materials Science, Kaunas University of Technology, K. Baršausko St. 59, 51423 Kaunas, \\ Lithuania; Tadas.Juknius@ktu.edu (T.J.); Ausrine.Jurkeviciute@ktu.lt (A.J.); Sigitas.Tamulevicius@ktu.lt (S.T.) \\ 2 Veterinary Academy, Lithuanian University of Health Sciences, Tilžès St. 18, 47181 Kaunas, Lithuania; \\ Modestas.Ruzauskas@lsmuni.lt (M.R.); Rita.Siugzdiniene@lsmuni.lt (R.Š.); Indre.Jukniene@fc.lsmuni.lt (I.J.); \\ Andrius.Vasiliauskas@ktu.lt (A.V.) \\ 3 Department of Physics, Kaunas University of Technology, Studentu St. 50, 51368 Kaunas, Lithuania \\ * Correspondence: Tomas.Tamulevicius@ktu.lt; Tel.: +370-37-313-432
}

Academic Editor: Mauro Pollini

Received: 31 March 2016; Accepted: 10 May 2016; Published: 13 May 2016

\begin{abstract}
In the current work, a new antibacterial bandage was proposed where diamond-like carbon with silver nanoparticle (DLC:Ag)-coated synthetic silk tissue was used as a building block. The DLC:Ag structure, the dimensions of nanoparticles, the silver concentration and the silver ion release were studied systematically employing scanning electron microscopy, energy dispersive X-ray spectroscopy and atomic absorption spectroscopy, respectively. Antimicrobial properties were investigated using microbiological tests (disk diffusion method and spread-plate technique). The DLC:Ag layer was stabilized on the surface of the bandage using a thin layer of medical grade gelatin and cellulose. Four different strains of Staphylococcus aureus extracted from humans' and animals' infected wounds were used. It is demonstrated that the efficiency of the $\mathrm{Ag}^{+}$ion release to the aqueous media can be increased by further RF oxygen plasma etching of the nanocomposite. It was obtained that the best antibacterial properties were demonstrated by the plasma-processed DLC:Ag layer having a 3.12 at \% Ag surface concentration with the dominating linear dimensions of nanoparticles being $23.7 \mathrm{~nm}$. An extra protective layer made from cellulose and gelatin with agar contributed to the accumulation and efficient release of silver ions to the aqueous media, increasing bandage antimicrobial efficiency up to $50 \%$ as compared to the single DLC:Ag layer on textile.
\end{abstract}

Keywords: nanocomposite; silver; bandage; antimicrobial; S. aureus

PACS: 81.07.-b; AGRICOLASCC: L832

\section{Introduction}

Quite often, due to bad care of a wound (or a weak immune system), pathogenic microorganisms cause wound inflammation. Bacteria, like methicillin-resistant Staphylococcus aureus (MRSA), can cause severe infections with bad prognosis and consequences [1-3]. On the other hand, small wounds after injuries can be healed using simple cotton bandages, which usually do not protect the damaged tissues from bacteria and secondary infection.

It is known that bacterial adhesion is the first step in colonization of wounded skin and the formation of a biofilm [4]. Therefore, it is very important to have the antibacterial surface directly on the bandage to avoid the formation of these bacteria films, preventing bacteria multiplication inside the bandage [5]. Bacterial infections are usually treated with antibiotics; however, a good effect 
is not obtained in every case, and this is because many bacteria are immunized to antibiotics after being subjected to the treatment [6]. Moreover, antimicrobial resistance is directly associated with over-usage of antibiotics; thus, alternative methods for treatment are necessary. One of the most important pathogenic bacteria associated with different types of infections, including skin and soft tissues, is S. aureus [7]. Infections caused by this species sometimes are very hard to treat because of its multiple-resistance. Due to this reason, $S$. aureus is reputed as one of the most intractable pathogenic bacteria in the history of antibiotic chemotherapy [8].

The closure of wounds and fistulas using silver sutures was shown to be very successful in preventing infections [9]. Silver can be applied in different forms, namely as a metal, as a compound or as a free dissolved ion. The famous Hippocrates first described silver's antimicrobial properties in $400 \mathrm{BC}$ [10]. The ancient users of silver had no idea what form of silver worked best, but they just observed the positive effects of silver and silver salts. They also realized that silver worked best when some moisture was present. Now, it is proven that the silver ions $\left(\mathrm{Ag}^{+}\right)$are responsible for the antimicrobial activity [11]. It is known that silver is an antiseptic metal and can act against bacteria in different ways due to $\mathrm{Ag}$ cation release in aqueous media. $\mathrm{Ag}^{+}$can destruct the cell membranes, destroy the respiratory enzyme system or can block DNA replication. This variability of antibacterial mechanisms of $\mathrm{Ag}$ hinders bacterial resistance formation [12]. The possible antibacterial action mechanisms of silver nanoparticles (Ag NPs) are explained in the following way. $\mathrm{Ag}^{+}$ions are supposed to bind to sulfhydryl groups, which lead to protein denaturation by reducing disulfide bonds; $\mathrm{Ag}^{+}$can complex with electron donor groups containing sulfur, oxygen or nitrogen that are normally present as thiols or phosphates on amino acids and nucleic acids [13]. Ag NPs react with sulfur-rich proteins in the bacteria cell membrane and the interior of the cell or with phosphorous-containing compounds, such as DNA. Accordingly, the morphological changes in the bacteria cell membrane and the possible damage of DNA caused by the reaction with Ag NPs disturb the respiratory chain or cell division processes, leading to cell death [14]. The antibacterial activity of a zero-valent silver phase strictly depends on the surface development of the solid, since silver atoms/ions required to accomplish the antibacterial activity are released only from the surface. Consequently, when this solid phase is in a powdered form, the resulting antibacterial activity can be significantly increased, and an ultrafine silver powder may result in several orders of magnitude more activity than the corresponding bulk solid [15]. The Ag NPs are known to oxidize to Ag ions when they interact with water molecules. Ag nanoparticles could provide sustained release of sufficient Ag ion compared to $\mathrm{Ag}$ salts and bulk metallic forms due to higher active surface to volume ratios [16]. Finally, the nanosized silver antibacterial activity is enhanced for two main reasons: the fraction of surface silver atoms increases with decreasing particle size, and a greater fraction of surface silver atoms is weakly bonded to the particle surface, which can be easily released to the surrounding medium. It is agreed that the Ag NP nanocomposite antimicrobial activity is basically related to its ability to release $\mathrm{Ag}^{+}$over time [15].

The amount of biotechnological products containing silver nanoparticles in their composition is increasing every day. For example, they are being used in the impregnation of wound dressings, medical devices, dental materials, fabrics, among others, besides the combination with antibiotics for the observation of a synergistic antibacterial effect [13]. Because of the increased attention to antibacterial nanocomposites in the last few decades, there is significant interest in studying Ag ion release from Ag NPs to optimize the nanocomposite performance and to reduce the negative effects on human cells and the environment [17]. Ag nanoparticles have to be placed in media or on a surface, which could have direct contact with skin tissues [18]. As an example, synthetic silk can be rinsed in colloidal silver solution and, later on, dried out. However, in such a case, due to rinsing, less Ag nanoparticles remain, and finally, the surface is polluted with the remainder of the chemicals used in the process [19]. Therefore, this technology is not suitable for bandages. Antibacterial surfaces can be produced, as well as a coating, where Ag-containing coatings can be envisaged as a pure Ag layer, or Ag nanoparticles embedded in a matrix [12]. 
In this case, diamond-like carbon (DLC) can be considered as a candidate, as it is known as a versatile coating material that finds a variety of biomedical applications, including endoprosthesis and dental implants. It provides mechanical robustness and cell-compatibility at the same time. To broaden this range of beneficial properties even more, trials were reported when silver or silver nanoparticles were embedded in order to add antibacterial properties [4,20].

Considering the final product, it should be mentioned that now, some bandages with silver-coated textile are available on the market [21-23], where a thin silver layer is used that may release silver ions if moisture is present. Some manufacturers offer hydrogel-based wound dressings [24,25], where the hydrogel material is saturated with silver ions. In addition, hydrogel contains water and crosslinked molecules, the structure of which ensures moisture absorption [26].

In the current work, DLC:Ag nanocomposite films were deposited on textile (synthetic silk) as a part of a smart bandage prototype demonstrating antibacterial properties. The antibacterial properties of such nanocomposites were systematically tested against $S$. aureus emphasizing conditions of DC magnetron sputtering and, further, plasma processing steps. DLC:Ag properties were characterized employing scanning electron microscopy (SEM) with energy dispersive X-ray spectroscopy (EDS) and atomic absorption spectroscopy (AAS). Further development of the smart bandage by integrating new functionalities is in progress and will be published in the forthcoming publications.

\section{Results}

\subsection{Structure and Composition of DLC:Ag Layers Deposited on Textile and Crystalline Silicon}

From the EDS measurements, it was obtained that the chemical content of Ag in as-deposited DLC:Ag films varies from $0.46-6.43$ at \% (Table 1 ).

Table 1. Averaged DLC:Ag chemical composition obtained with EDS.

\begin{tabular}{cccc}
\hline Sample No. & Carbon (at \%) & Silver (at \%) & Oxygen (at \%) \\
\hline 1 & $67.54 \pm 1.33^{1}$ & $0.46 \pm 0.02$ & $32.01 \pm 1.33$ \\
2 & $61.55 \pm 0.58$ & $3.12 \pm 0.11$ & $31.16 \pm 4.65$ \\
3 & $48.92 \pm 3.65$ & $6.43 \pm 0.65$ & $44.65 \pm 4.27$ \\
\hline \multicolumn{4}{c}{ Uncertainty is one standard deviation. }
\end{tabular}

SEM measurements revealed that the lowest Ag content films do not have visible Ag nanoparticles on the surface (Sample 1). A few particles were visible only on the surface of the silk substrates (see Figure 1a) that were not present prior to deposition. The middle and highest investigated Ag concentration samples (Samples 2 and 3) had a number of silver clusters on the surface (Figure 1b,c). SEM micrographs and NP analysis are depicted in Figure 1.
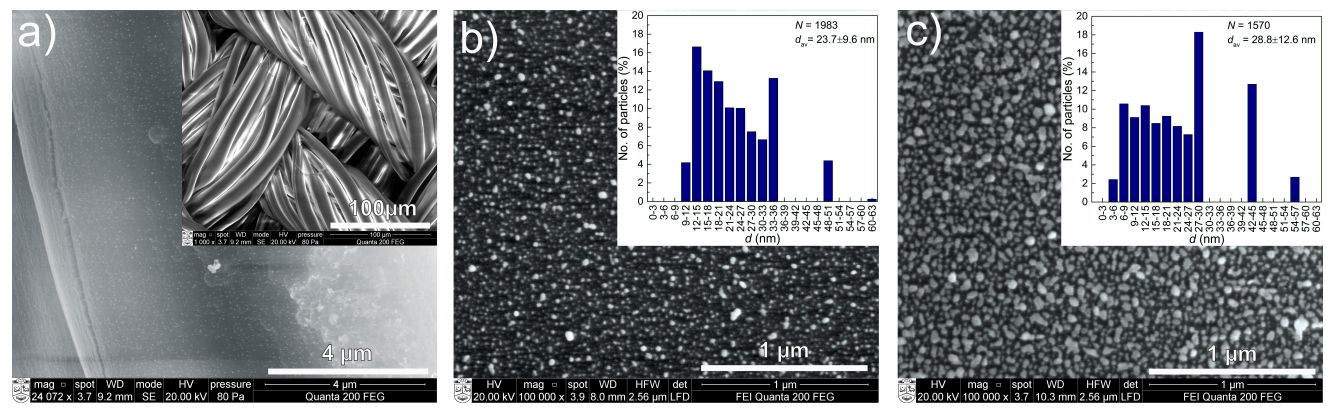

Figure 1. SEM micrographs of DLC:Ag films of different Ag content on different substrates: (a) lowest Ag content film (Sample 1; scale bar: $4 \mu \mathrm{m}$ ) on silk; the inset depicts the silk structure (scale bar: $100 \mu \mathrm{m}$ ); $(\mathbf{b}, \mathbf{c})$ summarize the information about the medium and highest Ag concentration film (Samples 2 and 3, respectively; scale bar: $1 \mu \mathrm{m}$ ) on silicon substrates; insets depict the particle size distribution number of analyzed particles $(N)$ and the average particle diameters $\left(d_{\mathrm{av}}\right)$ of the corresponding SEM micrographs. 


\subsection{Antimicrobial Activity of Virgin and $\mathrm{RF} \mathrm{O}_{2}$ Plasma Processed DLC:Ag Films}

Three as-deposited and $\mathrm{O}_{2}$ plasma-processed DLC:Ag thin films containing different amounts of Ag 0.5-6.0 at \% deposited on synthetic silk were investigated employing the disk diffusion method. Figure 2 demonstrates the results of antimicrobial activity for Samples 1-3.
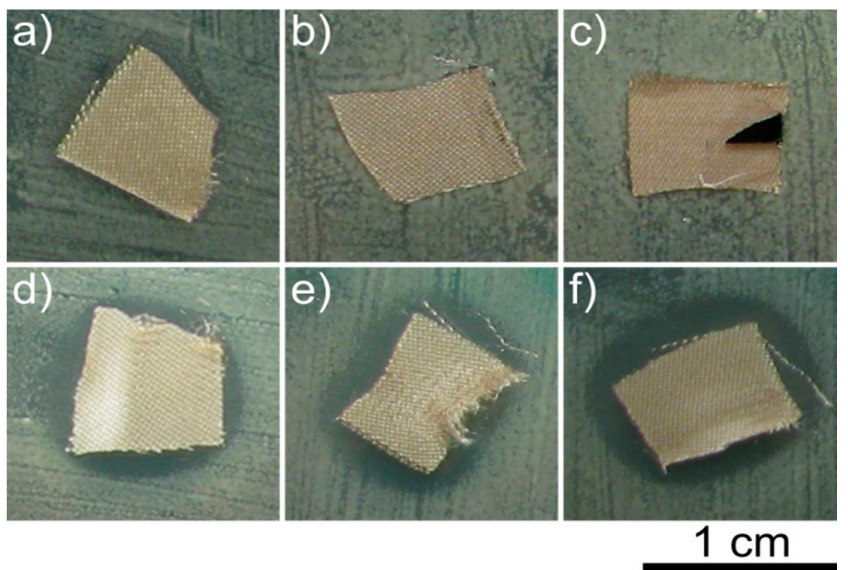

Figure 2. Testing of antimicrobial properties with the S. aureus LTSaM01 strain bacteria (disk diffusion method) of virgin Samples 1 (a); 2 (b) and 3 (c); as well as after 20-s plasma processing $((\mathbf{d}-\mathbf{f})$ respectively). The clear zone in $(\mathbf{d}-\mathbf{f})$ indicates areas where no bacteria multiplication is observed.

One can see that the virgin DLC:Ag-coated sample does not show an expressed bacteria inhibition area for the $S$. aureus LTSaM01 strain (the same results were found for all investigated strains around the samples in the Petri dishes), while the $\mathrm{O}_{2}$ plasma-processed sample demonstrates up to a 2.5-mm inhibition zone.

The inhibition zones' dimensions measured with four different strains after different processing duration with $\mathrm{O}_{2}$ plasma for three different $\mathrm{Ag}$ concentration samples on silk are depicted in Figure 3 .
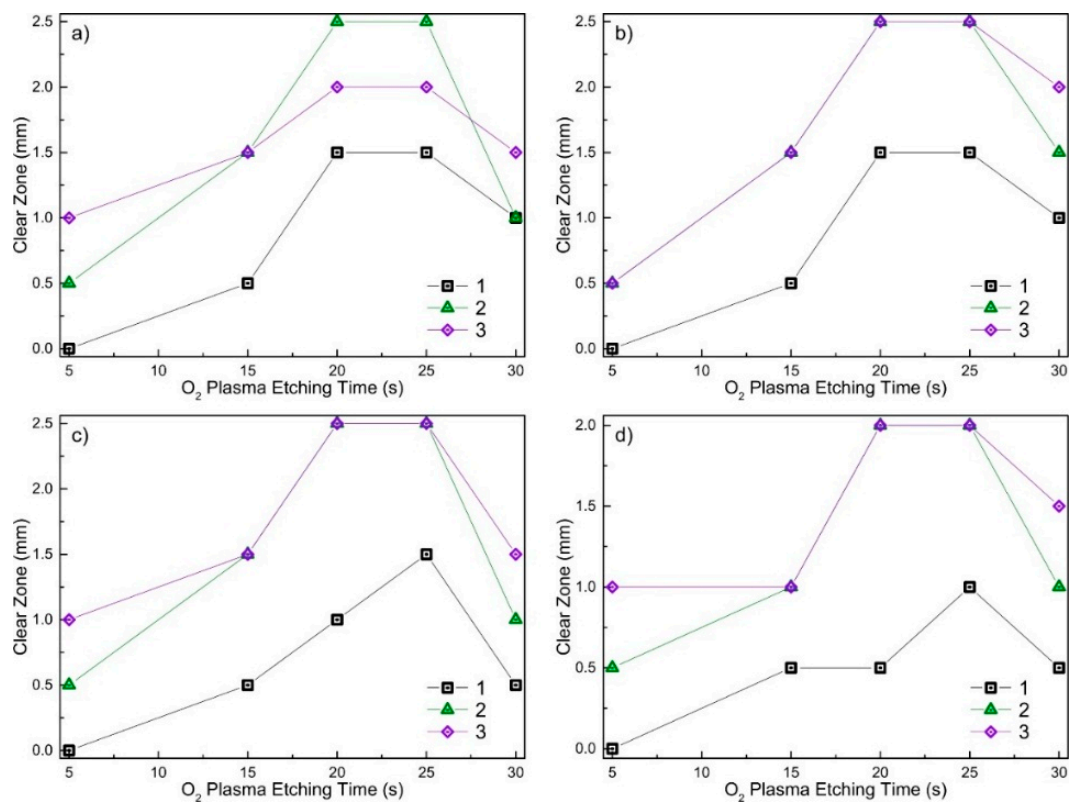

Figure 3. Antimicrobial effect (linear dimensions of the clear zone) for three different Ag concentration DLC:Ag films deposited on silicon and processed with $\mathrm{O}_{2}$ plasma for different durations (5-30 s) (Samples 1-3) were tested with four different S. aureus bacteria strains, (a) LTSaDA01; (b) LTSaM01; (c) LTSa635 and (d) LTSa603, the employing disk diffusion method. Measurement uncertainty: $0.5 \mathrm{~mm}$. 
From Figure 3, one can see that after $5 \mathrm{~s}$ of $\mathrm{O}_{2}$ plasma etching, Sample 1 showed no antimicrobial effect with all investigated bacteria strains. Sample 2 had only a weak effect for all bacteria strains, i.e., the inhibition zone was $\leqslant 0.5 \mathrm{~mm}$ (see Figure 3). Sample 3 with 6.43 at $\%$ of silver has shown even better results with the shortest plasma processing duration, i.e., the inhibition zone was $1 \mathrm{~mm}$, except bacteria LTSaM01 (see Figure 3b), where a clear zone of $0.5 \mathrm{~mm}$ was obtained. After $15 \mathrm{~s}$ of etching in $\mathrm{O}_{2}$ plasma, Sample 1 had a visible antimicrobial effect for all bacteria strains; the inhibition zone was $0.5 \mathrm{~mm}$. Samples 2 and 3 demonstrated a larger inhibition zone: $1.5 \mathrm{~mm}$; except strain LTSa603 (see Figure 3d), where the inhibition zone was $1 \mathrm{~mm}$. The best results in terms of inhibition zone were observed for the samples etched for $20 \mathrm{~s}$ and $25 \mathrm{~s}$. As can be seen from Figure $2 \mathrm{~d}-\mathrm{f}$ and Figure 3 , plasma etching strongly increased the inhibition effect for all four $S$. aureus strains for all investigated samples with different Ag content nanocomposite DLC:Ag films.

The antimicrobial effect of differently plasma-processed DLC:Ag nanocomposite films on the investigated strains could be related to the surface morphology changes and opening of the Ag NPs' surface from the DLC matrix (see Figure 4). The chemical composition of the films after different $\mathrm{O}_{2}$ plasma processing, providing the characteristic weak and strong antimicrobial effects on the investigated bacteria strains, is depicted in Figure 5.
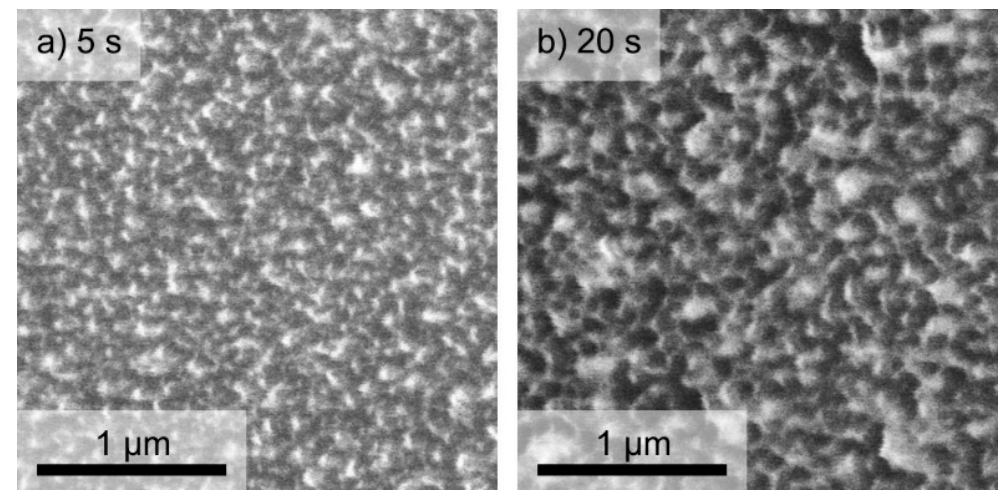

Figure 4. SEM micrographs of DLC:Ag (Sample 2) after different durations of $\mathrm{O}_{2}$ processing: (a) $5 \mathrm{~s}$; (b) $20 \mathrm{~s}$. Scale bar: $1 \mu \mathrm{m}$.
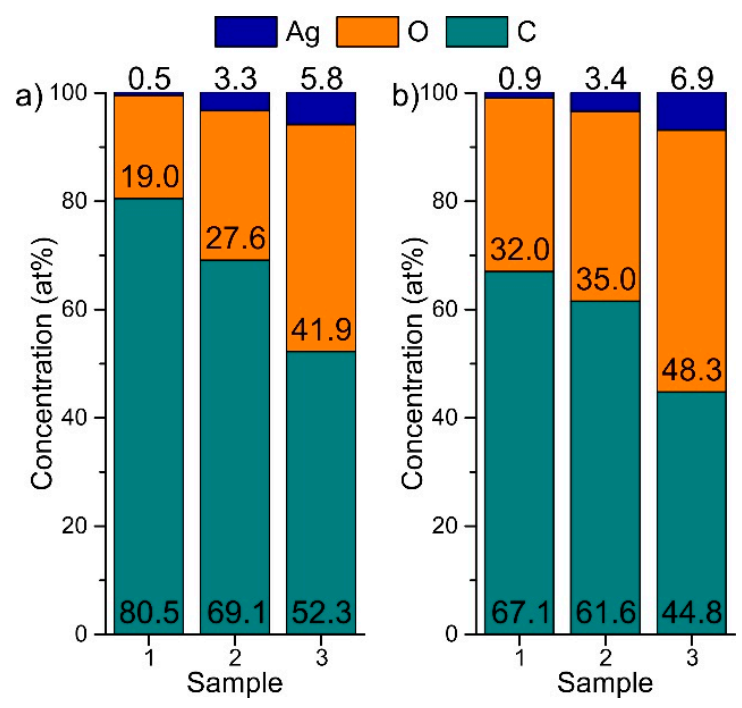

Figure 5. Chemical composition of DLC:Ag films (Samples 1-3) after $5 \mathrm{~s}(\mathbf{a})$ and $20 \mathrm{~s}(\mathbf{b})$ of $\mathrm{O}_{2}$ plasma processing. 
From Figure 5, one can see that after $\mathrm{O}_{2}$ plasma processing, the surface concentration of carbon decreases and the amount of silver increases. Analysis of the composition of the films has shown a relatively high concentration of oxygen in the films as deposited and exposed to oxygen plasma. Unfortunately, these measurements were done after a long exposure of the samples in atmosphere, and potential changes of oxygen concentration in the films were hindered by the surface adsorption processes. Therefore, these values probably could be considered only to identify possible trends of variations but not the absolute (relative) concentration of oxygen.

\subsection{Antimicrobial Activity of Bandage Prototype}

Based on the best antimicrobial activity results, the 20 s plasma-processed DLC:Ag nanocomposite film containing 3.12 at $\% \mathrm{Ag}$ was selected for further investigation as a building block of the bandage prototype. Synthetic silk substrate was used as a DLC:Ag substrate. A protective layer from cellulose sheet $(0.01 \mathrm{~mm})$ gelatin $(0.1-0.15 \mathrm{~mm})$ worked as a silver ion accumulation matrix and prevented the bandage from sticking to the wound's soft tissues. The antimicrobial properties of the prepared prototype were tested using the spread plate technique.

ASS experiments were used to follow the silver ion extraction process from the prototype containing the DLC:Ag nanocomposite layer. Figure 6 depicts silver ion concentration changes for different soaking durations of Sample 2 in purified water.

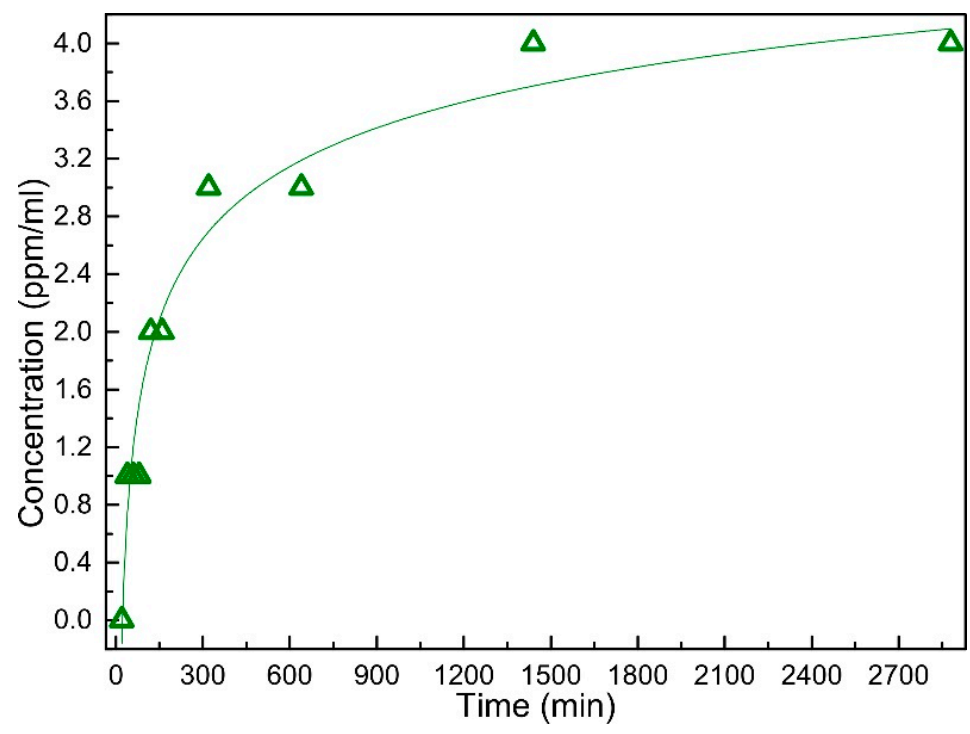

Figure 6. Silver ion concentration in purified water after soaking of synthetic silk coated with DLC:Ag (Sample 2 (3.12 at \% Ag)) for different time durations obtained with AAS.

It was obtained that the silver ion concentration increases sharply during the first $300 \mathrm{~min}$ and saturates approximately after $900 \mathrm{~min}$. A double logarithm function $(y=\mathrm{a} \times \ln (-\mathrm{b} \times \ln (x)))$ can be used to approximate the experimental curve, and a high correlation coefficient $R^{2}=0.96$ was obtained for the constants $\mathrm{a}=4.36$ and $\mathrm{b}=-0.32$.

Antimicrobial testing results of the smart bandage without and with the protective layer obtained using the spread-plate technique with four bacteria strains are summarized in Figure 7.

It was found that the exponential law (equation: $y=y_{0}+A \times \exp \left(R_{0} \times x\right)$ could be used to describe the time dependencies of CFU versus time, and Table 2 summarizes the values of the coefficients used in the approximations. 

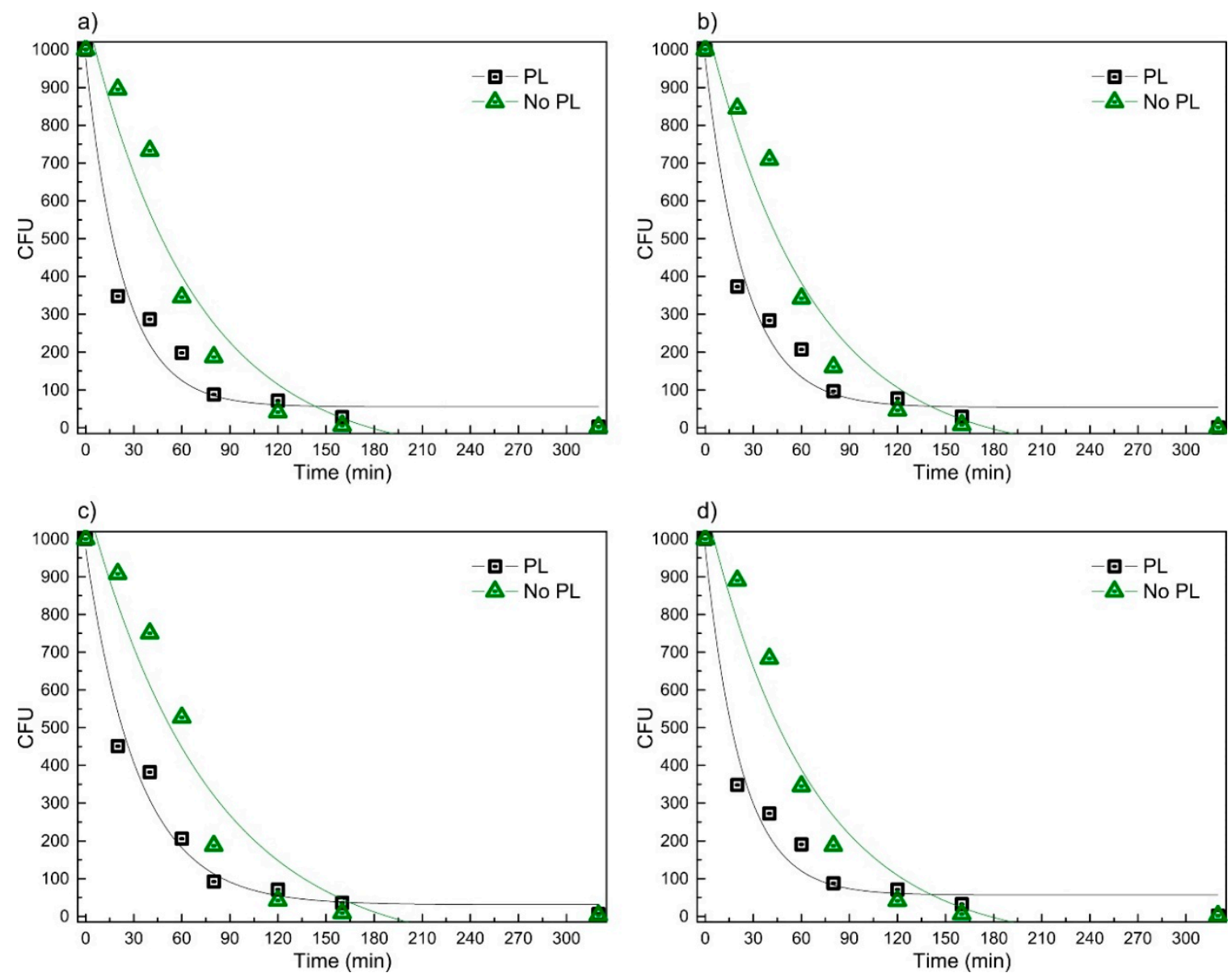

Figure 7. Time dependencies of bacteria colony forming units (CFU) versus time using the spread-plate technique for the bandage prototype (PL) and the reference sample (No PL) measured with four types of S. aureus bacteria strains: (a) LTSaDA01; (b) LTSaM01; (c) LTSa635 and (d) LTSa603.

Table 2. Coefficients of exponential dependencies used in the approximations of CFU versus time for four types of $S$. aureus bacteria strains.

\begin{tabular}{cccccccccc}
\hline \multirow{2}{*}{$\begin{array}{c}\text { Sample } \\
\text { Structure }\end{array}$} & \multirow{2}{*}{$\begin{array}{c}\text { Fitting } \\
\text { Coefficients }\end{array}$} & \multicolumn{2}{c}{ LTSaDA01 (a) } & \multicolumn{2}{c}{ LTSaM01 (b) } & \multicolumn{2}{c}{ LTSa635 (c) } & \multicolumn{2}{c}{ LTSa603 (d) } \\
\cline { 2 - 10 } & Value & S.E. ${ }^{\mathbf{1}}$ & Value & S.E. & Value & S.E. & Value & S.E. \\
\hline \multirow{4}{*}{ PL } & $y_{0}$ & 55.37 & 36.36 & 54.13 & 34.42 & 30.77 & 35.16 & 56.566 & 33.60 \\
& $A$ & 921.2 & 74.29 & 922.4 & 68.84 & 943.4 & 61.89 & 922.87 & 69.53 \\
& $R_{0}$ & -0.0430 & 0.00826 & -0.0407 & 0.00717 & -0.0305 & 0.00463 & -0.0445 & 0.00803 \\
& $R^{2}$ & \multicolumn{2}{c}{0.956} & \multicolumn{2}{c}{0.962} & 0.971 & 0.961 \\
\multirow{4}{*}{ No PL } & $y_{0}$ & -83.45 & 110.3 & -75.39 & 97.95 & -101.1 & 130.6 & -77.21 & 95.29 \\
& $A$ & 1184.3 & 134.41 & 1157.7 & 121.45 & 1208.68 & 149.92 & 1170.6 & 117.74 \\
& $R_{0}$ & -0.0149 & 0.00408 & -0.0154 & 0.0039 & -0.0132 & 0.00397 & -0.0153 & 0.00371 \\
& $R^{2}$ & \multicolumn{2}{c}{0.919} & \multicolumn{2}{c}{0.930} & 0.908 & 0.936 \\
\hline
\end{tabular}

${ }^{1}$ Standard Error.

Tests with bacteria LTSaDA01, LTSaM01 and LTSa603 revealed that after $20 \mathrm{~min}$, DLC:Ag-coated synthetic silk without PL killed $10 \%-15 \%$ of $S$. aureus bacteria, when the same material with PL killed $63 \%-65 \%$. Tests with LTSa635 (MRSA) for the same duration of time have shown efficiencies of $9 \%$ and $55 \%$, respectively. Results of the longest soaking duration for 320 min revealed that the bandage without PL had the same antimicrobial effect as compared to the bandage plated with PL, i.e., after bandages, in both cases, $99 \%$ of all bacteria were killed, and only a few CFU were observed. 


\section{Discussion}

As was presented above, DC-reactive magnetron sputtering appears as an efficient way to produce nanocomposite DLC:Ag coatings. Simple variation of the $\mathrm{Ar} / \mathrm{C}_{2} \mathrm{H}_{2}$ flux ratio enables the deposition of films with variable content of silver nanoparticle filler embedded in DLC matrix. The typical structure of the DLC:Ag films deposited under similar conditions can be found in [27]. Similar results were reported, as well, by [28], where DC-reactive unbalanced magnetron sputtering of Ag target in acetylene atmosphere allowed producing DLC:Ag nanocomposite thin films with a variable content of silver. During the experiments, the thickness of the film deposited on crystalline silicon and textile was approximately $40 \mathrm{~nm}$, and according to Figure $1 \mathrm{~b}, \mathrm{c}$, the average size of silver nanoparticles varied within a range $2-63 \mathrm{~nm}$. In the case of lower silver concentration, low dimension silver nanoparticles prevailed. The average diameters of silver nanoclusters in DLC:Ag nanocomposite films were $23.7 \mathrm{~nm}$ and $28.8 \mathrm{~nm}$ for Samples 2 and 3, respectively. The larger silver content in the coatings matrix correlated with larger silver cluster diameter. This is in good agreement with our previous experiments, where we have performed deposition of DLC:Ag nanocomposites on silica substrates [29,30].

Antimicrobial results demonstrated that as-deposited DLC:Ag samples with low silver concentration (Samples 1-3) had no or only very weak antimicrobial effect (see Figure 2). As we have defined, additional $\mathrm{O}_{2}$ plasma etching appears as an efficient tool in enhancing the antibacterial effect of the DLC:Ag nanocomposite surface. According to the results presented in Figure 5, $\mathrm{O}_{2}$ plasma processing reduces the carbon surface concentration and provides the developed nanocomposite surface (Figure 4), which seems close to the results obtained in [31], where $\mathrm{O}_{2}$ etching of organic materials provided nanotextured surfaces. It should be noted that plasma etching for $20 \mathrm{~s}$ reduced carbon content by $13.9 \%$ on average. During this process, a thin layer of carbon from the DLC:Ag surface was removed to expose more silver nanoparticles, which were embedded and covered by the DLC matrix [32]. On the other hand, due to $\mathrm{O}_{2}$ plasma bombardment, coalescence of silver particles [33] and partial oxidation of silver nanoparticles take place. From this point of view, Sample 2 appears to be more efficient as compared to Sample 3 in terms of antimicrobial properties due to the smaller size of the nanoparticles. The dominating mechanisms could be elucidated after more comprehensive analysis of the behavior of DLC:Ag, and these experiments are in progress. After the oxygen plasma etching procedure, the average silver content increased by 0.5 at $\%$ after $20 \mathrm{~s}$. The reduction of Ag in DLC:Ag films in the case of the highest silver concentration (Sample 3) could be explained by volume expansion and strain-induced cracking of oxidized Ag NPs due to oxygen ion bombardment [34,35]. Probably, a high concentration of silver, as well as an increase of the size of the nanoparticles in the case of Sample 3 (as compared to the other two samples) contribute to the efficiency of the mentioned mechanism. According to [36], the improvement of antimicrobial properties correlates with the increased hydrophobicity and, according to our findings, with the increased surface concentration of silver, as well.

As one can see, the etching time affected structural surface changes (Figure 4). Comparing samples etched for $5 \mathrm{~s}$ and as-deposited samples, only minor surface changes were observed, but the samples exposed to $\mathrm{O}_{2}$ plasma for the longer time had many small dimples instead of a smooth surface. According to [36], this surface process is defined by the reaction of carbon materials, like DLC films with oxygen plasma, where plasma produces a destruction of the graphite rings. This results in an increase of single carbon chains where the concentration of aliphatic carbons atoms is pre-dominant in $\mathrm{O}_{2}$ plasma-treated DLC films. Oxygen plasma treatment makes the DLC surface more desorbed, rougher and superhydrophilic [36]. Finally, the superhydrophilic surface ensured maximum silver ion diffusion from the samples to wet agar media. On the other hand, we have found that the prolonged plasma exposure (above $25 \mathrm{~s}$ ) resulted in the decrease of antibacterial activity for all investigated strains and investigated silver concentrations (see Figure 3). This effect could be attributed to the ion beam irradiation-induced increase of silver nanoparticles (ripening process) that we have observed early in the case of reactive ion etching of DLC:Ag nanocomposites [33]. One can expect that the larger particles have a smaller surface area, which is responsible for silver ion release into media. The nanoparticle 
size effect on the antimicrobial properties was reported as well in $[37,38]$, where the authors declare better antibacterial properties of small dimensions of AgNPs.

According to our findings, the optimal time for RF oxygen plasma etching was 20-25 s (see Figure 3). For such plasma exposure, all of the coatings with different silver content revealed the best antimicrobial properties, i.e., they had the developed surface and optimum dimensions of the silver nanoparticles.

For such kinds of samples (Sample 2 as a typical example was taken (silver content after $20 \mathrm{~s}$; etching was 3.41 at \%)), AAS analysis revealed efficient silver ion migration into aqueous media (Figure 6). We found out that saturation of silver ion concentration in purified water takes place, and after $24 \mathrm{~h}$, at a $35{ }^{\circ} \mathrm{C}$ temperature, it reaches $4 \mathrm{ppm}$. It should be noted that according to [38], the antibacterial activity against $S$. aureus starts at about $1 \mathrm{ppm}$. These results correlate well with the microbiological testing (spread-plate technique; Figure 7) data where larger silver concentrations killed more bacteria, as well.

Experimental data (Figure 7) revealed that the bandage without PL (soaking duration of $20 \mathrm{~min}$ ) demonstrated a lower antimicrobial effect as compared to the bandage where PL was applied. One can assume that our chosen aqueous media (PL) can accumulate silver ions inside. After $24 \mathrm{~h}$ of exposure of the bandage, the PL has accumulated silver ions and during the test acted as an efficient source of silver ions. Moreover, the agar-gelatin layer at $35^{\circ} \mathrm{C}$ can dissolve easily, and silver ions can spread rapidly to all aqueous media, providing a very good antimicrobial effect. In all studied cases, PL technology improved the antibacterial properties of the bandage, and it was more than approximately $50 \%$ effective during the same time interval. The action speed was the main advantage of the prototype, i.e., PL can be used as silver ion accumulation media for fast ion release in aqueous media, enabling to kill instantly more than $50 \%$ of all of the bacteria population. It should be noted that in wound healing, this is a very important factor, as the bacteria need to be killed in a short period of time to prevent efficient growth of the bacteria population [39-41]; e.g., in [16], it was shown that bacterial adhesion involved reversible bacterial association in the first $1-2 \mathrm{~h}$ after post-implantation, followed by stronger bacterial adhesion, approximately $2-3 \mathrm{~h}$ later. After $24 \mathrm{~h}$, certain bacteria formed a biofilm, which was resistant to host defense and systemic antibiotic treatment.

In addition to the efficient antimicrobial properties, our bandage with PL having a gel-like structure with the synthetic silk skeleton ensures good mechanical properties, as well. The cellulose sheet as the membrane can sustain small particles and debris inside the bandage close to the DLC:Ag surface, avoiding wound contamination. The gelatin and agar layer has very good water absorption abilities, as was demonstrated in [42]. Furthermore, according to [14], approximately 39\% more silver is released into alkaline sweat $(\mathrm{pH} \mathrm{8.0)}$ as compared to acidic sweat ( $\mathrm{pH}$ 5.5). In infected wound, $\mathrm{pH}$ usually moves to a neutral or slightly alkali $\mathrm{pH}$ value; in that case, our technology also has an advantage: silver ions should migrate faster, from nanoparticles inside the DLC matrix, and the antimicrobial effect could be even stronger comparing to the tests in saline solution (0.9\%) [14]. The higher release rate of $\mathrm{Ag}$ ion concentration into the surrounding medium and the longer it is sustained, the more thorough the antimicrobial effect will be [43].

It should be noted as well that cytotoxicity is one of the main problems with using nanotechnology in medical devices like bandages. Embedded cells like nanoparticles can cause adverse side effects to the organism. In our bandage prototype, only the PL structure was used, to avoid this problem, but further tests are needed to investigate toxicity. In the prototype bandage, the silver ion concentration, according to the AAS data, could reach $4 \mathrm{ppm}$ or $4 \mu \mathrm{g} / \mathrm{mL}$. According to [13], the minimum inhibitory concentrations of all bacteria tested were in a concentration range of AgNPs (between 3.37 and $13.5 \mu \mathrm{g} / \mathrm{mL}$ ) in which there was no observed significant cytotoxic activity compared to the control [13]. 


\section{Materials and Methods}

\subsection{Deposition, Characterization and $\mathrm{O}_{2}$ Plasma Processing of DLC:Ag Films}

DLC:Ag coatings with different Ag content were deposited on textile (twill weaved synthetic silk, with a weft density of $110 \mathrm{~cm}^{-1}$ and a warp density of $100 \mathrm{~cm}^{-1}$ ) by DC-reactive unbalanced magnetron sputtering of Ag target in acetylene atmosphere. Ag content was controlled varying feed stock gas flow rates and changing magnetron power, as well as bias voltage. Crystalline silicon wafer substrates were used as well for the comparative control of the deposition process. The deposition conditions are summarized in Table 3. Further details on the deposition and properties of DLC:Ag coatings with variable silver concentration can be found in our early papers $[33,44,45]$.

Table 3. Deposition conditions of DLC:Ag films.

\begin{tabular}{cccccc}
\hline Sample No. & $\begin{array}{c}\text { Sputtering } \\
\text { Duration (s) }\end{array}$ & $\begin{array}{c}\text { Ar Gas Flow } \\
\mathbf{( s c c m )}\end{array}$ & $\begin{array}{c}\mathbf{C}_{\mathbf{2}} \mathbf{H}_{\mathbf{2}} \text { Gas } \\
\text { Flow (sccm) }\end{array}$ & $\begin{array}{c}\text { Magnetron } \\
\text { Voltage (V) }\end{array}$ & $\begin{array}{c}\text { Magnetron } \\
\text { Current (A) }\end{array}$ \\
\hline 1 & 520 & 70 & 21.1 & $553-625$ & $0.07-0.12$ \\
2 & 235 & 70 & 21.1 & $568-741$ & $0.07-0.22$ \\
3 & 200 & 80 & 7.8 & $625-656$ & $0.10-0.11$ \\
\hline
\end{tabular}

The thickness of the deposited DLC:Ag coatings was approximately $40 \mathrm{~nm}$ (as measured by scanning electron microscope (SEM)). The AgNPs' particle size distribution and chemical composition were obtained employing SEM FEI Quanta 200 FEG with an energy dispersive X-ray spectrometer (EDS), Bruker Quantax. NPs' diameters and the chemical composition of the films were studied for the DLC:Ag samples deposited on Si substrates. EDS measurements were performed at a5-keV accelerating voltage in order to minimize the excitation of the Si $K_{\alpha}$ peak. NP size analysis was preformed employing ImageJ (NIH) software and custom MATLAB (MathWorks) code. More detailed information about the applied NP analysis procedures can be found elsewhere $[33,46]$. Measurements of as-deposited nanocomposite thin film were performed at 3-5 different points, and average normalized surface concentrations (excluding silicon) can be found in Table 1.

After the deposition, the samples were additionally etched by radio frequency (RF; $13.56 \mathrm{MHz})$ oxygen plasma (99.9\%) in $133 \mathrm{~Pa}$ pressure and $0.3 \mathrm{~W} / \mathrm{cm}^{2}$ power for 5-30 s. Morphology and antimicrobial properties of the as-deposited and $\mathrm{O}_{2}$ plasma-etched DLC:Ag films on silicon and silk were investigated.

\subsection{Microbiological Testing of Virgin and $\mathrm{O}_{2}$ Plasma-Processed DLC:Ag Films}

For testing of the bactericidal activity of DLC:Ag films on multiplying bacteria, four clinically-important strains causing skin and wound infections of $S$. aureus previously isolated at Lithuanian University of Health Sciences were selected. Two strains were isolated from sick humans (LTSaDA01 and LTSaM01), as well as two strains were isolated from diseased pet animals: a dog (LTSa603) and a cat (LTSa635). The strain LTSa635 was methicillin-resistant. The antimicrobial properties of the DLC:Ag layer, as well as bandage prototype including the DLC:Ag layer were tested using the disk diffusion method (see Figure 8a) and the spread-plate technique [47] (see Figure 8b). The bacterial suspension density of $1 \mathrm{McFarland}$ unit in saline solution $(0.9 \%)$ was prepared and inoculated onto Mueller Hinton agar (Thermo Scientific, Leicestershire, UK) in 94 mm-diameter Petri dishes. In the disk diffusion method, synthetic silk samples (virgin and etched) of a $6 \mathrm{~mm} \times 6 \mathrm{~mm}$ $( \pm 1 \mathrm{~mm})$ size with DLC:Ag coatings (Samples $1-3)$ were glued onto the agar surface using a small drop of water. The samples were incubated for $24 \mathrm{~h}$ at $35^{\circ} \mathrm{C}$. The dimensions of inhibition zones were measured from four sides of the sample, and the average value of the clear zone was calculated. To check the temporal stability of the coatings, experiments with all three different silver concentration DLC:Ag samples on synthetic silk were repeated for 4 times during a one-month period: at first day 
and thereafter at the 1st, 2nd and 3rd week after the deposition. Experimental results were fitted employing OriginPro (OriginLab, Northampton, MA, USA).

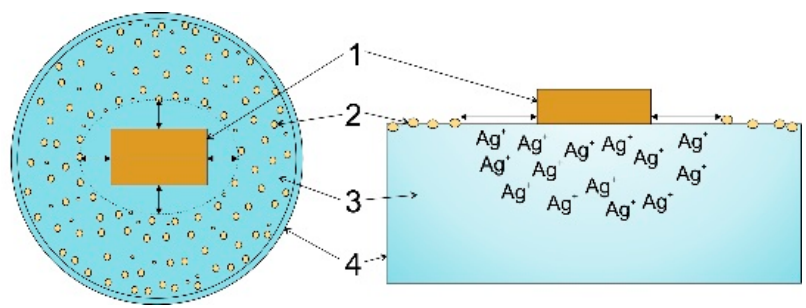

(a)

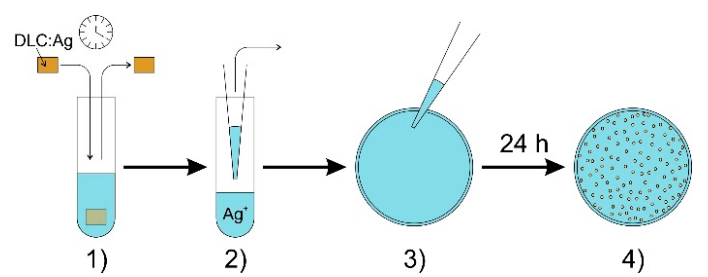

(b)

Figure 8. Antimicrobial testing techniques. (a) Schematics of the disk diffusion method used for microbiological testing ( $\mathrm{Ag}^{+}$diffusion of silver ions from the DLC:Ag surface into agar): (1) sample coated with DLC:Ag nanocomposite; (2) bacteria colonies; (3) agar (bacteria nutrition media); (4) Petri dish; (b) Schematics of the spread plate technique: (1) bandage prototype soaked in a test tube with bacteria saline solution for different time durations; (2) the bacterial solution with $\mathrm{Ag}^{+}$ions $(0.1 \mathrm{~mL})$ was transported into a Petri dish; (3) inoculation of bacteria onto the agar surface; (4) calculation of colony forming units (CFU).

\subsection{Construction of the Bandage Prototype}

DLC:Ag coating on synthetic silk indicated the best antimicrobial properties and was used as a part of the smart bandage. The coating was exposed to UV irradiation for disinfection. As a protective layer (PL), cellulose fibers (medium, C6288 Sigma, Sigma Aldrich, St. Louis, MO, USA), gelatin (53028 FLUKA, Sigma Aldrich) and agar (A1296 SIGMA, Sigma Aldrich) were used. A thin cellulose sheet, acting as a membrane, was manufactured from microfiber cellulose and gelatin as a gluing material. It was rolled into a $0.01 \mathrm{~mm}$-thick sheet. The cellulose sheet was glued using gelatin and pressed using a metal roller on DLC:Ag-coated synthetic silk. A hot suspension from gelatin and agar $(90 \% / 10 \%$, respectively) was prepared and placed on top as a second layer using a spin coater at low speed $(120 \mathrm{rpm})$. The structure of the smart bandage is presented in Figure 9. In such way, the prepared bandage prototype was used in the antibacterial tests after $24 \mathrm{~h}$.

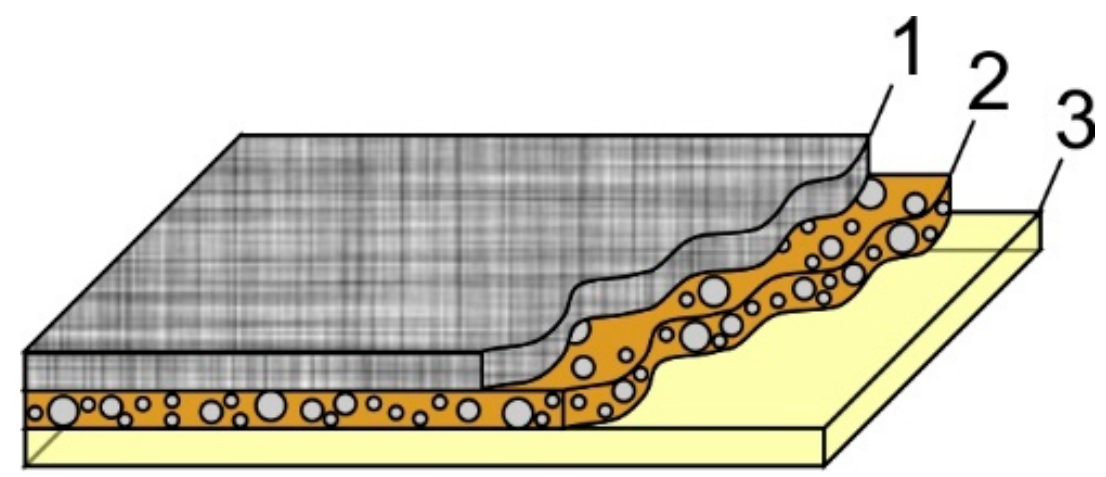

Figure 9. Principle structure of the proposed bandage: (1) synthetic silk substrate; (2) thin nanocomposite DLC:Ag films etched for $20 \mathrm{~s}$ in $\mathrm{O}_{2}$ plasma; (3) protective layer made from the thin cellulose sheet (membrane) and the gelatin layer.

\subsection{Antimicrobial Testing of the Bandage Prototype}

Bactericidal activity evaluation tests of the bandage prototype were carried out using the same four strains of S. aureus as described Section 4.2. The spread-plate technique [47] was applied to confirm the bandage's ability to kill bacteria on the surface and in the liquid media around it. The protective 
layer-covered rectangular-shaped bandage of $100 \mathrm{~mm}^{2}$ in area was soaked for 20, 40, 60, 80, 120, 160, $320 \mathrm{~min}$ in a thermostat at $35^{\circ} \mathrm{C}$ in a $1-\mathrm{mL}$ volume of bacteria in saline solution of $0.1 \mathrm{McFarland}$ units. To check the efficiency of the protective layer, an identical experiment was carried out with the bandage including just the nanocomposite layer (Sample 2 etched for $20 \mathrm{~s}$ ). After incubation, the withdrawn solution was diluted 1:1000 times, and thereafter, $100 \mu \mathrm{L}$ of bacteria suspension were inoculated onto a Petri dish containing Mueller Hinton. After $24 \mathrm{~h}$, colony forming units (CFU) were counted. For statistical reliability, this experiment was repeated 3 times.

\subsection{Antimicrobial Testing of the Bandage Prototype}

Atomic absorption spectroscopy (AAS) was used to identify $\mathrm{Ag}^{+}$migration from the bandage (synthetic silk with Ag nanoparticles) to ultrapure water. The disk-shaped $10-\mathrm{cm}^{2}$ bandage was soaked in the test tube with $10 \mathrm{~mL}$ of thermostated water at $35^{\circ} \mathrm{C}$ for time intervals from $20 \mathrm{~min}$ to $48 \mathrm{~h}$. Later on, water was filtrated from large $(0.1 \mathrm{~mm})$ particles, and AAS measurements were performed. A Perkin Elmer Model 403 spectrometer was employed.

\section{Conclusions}

Diamond-like carbon-based silver nanocomposite layers deposited by DC-reactive magnetron sputtering on textile appeared as an effective source of $\mathrm{Ag}^{+}$ions and demonstrated expressed antibacterial properties against four tested strains of Staphylococcus aureus bacteria.

The efficiency of the $\mathrm{Ag}^{+}$ion release to the aqueous media can be increased by further RF oxygen plasma etching of the nanocomposite. It was obtained that the best antibacterial properties were demonstrated by the plasma-processed DLC:Ag layer having a 3.12 at \% Ag surface concentration with the dominating linear dimensions of nanoparticles being $23.7 \mathrm{~nm}$.

An extra protective layer made from cellulose and gelatin with agar contributed to the accumulation and efficient release of silver ions to the aqueous media, increasing the bandage antimicrobial efficiency up to 50\% as compared to the single DLC:Ag layer on textile.

The proposed bandage prototype (having a silver ion concentration in the protective layer below the toxic level for organism cells) was able to kill more than $99.9 \%$ of all strains of bacteria after $320 \mathrm{~min}$, including methicillin-resistant Staphylococcus aureus.

Acknowledgments: This research was funded by the common Lithuanian University of Health Sciences and Kaunas University of Technology Research Project "NANOSMARTPLASTER" Grant No. PP38/152. No funds for covering the costs to publish in open access were received. Authors acknowledge Igoris Prosyčevas and Irina Abelit for atomic absorption spectroscopy measurements.

Author Contributions: S.T. and T.T. conceived of and designed the experiments. T.J., M.R., R.Š., I.J. and A.V. performed the experiments. A.J., T.J. and T.T. analyzed the data. T.T. and M.R. contributed reagents/materials/analysis tools. T.J. and T.T. wrote the paper.

Conflicts of Interest: The authors declare no conflict of interest.

\section{Abbreviations}

The following abbreviations are used in this manuscript

$\begin{array}{ll}\text { DLC } & \text { diamond-like carbon } \\ \text { DLC:Ag } & \text { diamond-like carbon with silver nanoparticles } \\ \text { RF } & \text { radio frequency } \\ \text { MRSA } & \text { methicillin-resistant Staphylococcus aureus } \\ \text { S. aureus } & \text { Staphylococcus aureus } \\ \text { Ag }^{+} & \text {silver ions } \\ \text { DNA } & \text { deoxyribonucleic acid } \\ \text { Ag NPs } & \text { silver nanoparticles } \\ \text { DC } & \text { direct current } \\ \text { PL } & \text { protective layer } \\ \text { SEM } & \text { scanning electron microscopy } \\ \text { EDS } & \text { energy dispersive X-ray spectroscopy } \\ \text { AAS } & \text { atomic absorption spectroscopy }\end{array}$




$\begin{array}{ll}N & \text { number of analyzed particles } \\ d_{\mathrm{av}} & \text { average particle diameter } \\ a & \text { constant } \\ b & \text { constant } \\ R^{2} & \text { correlation coefficient } \\ \mathrm{y}_{0} & \text { coefficient of extrapolation } \\ A & \text { coefficient of extrapolation } \\ R_{0} & \text { coefficient of extrapolation } \\ \text { S.E. } & \text { standard error }\end{array}$

\section{References}

1. Nanda, A.; Saravanan, M. Biosynthesis of silver nanoparticles from staphylococcus aureus and its antimicrobial activity against MRSA and MRSE. Nanomed. Nanotechnol. Biol. Med. 2009, 5, 452-456. [CrossRef] [PubMed]

2. Thomas, S. MRSA and the Use of Silver Dressings: Overcoming Bacterial Resistance. Available online: http:/ / www.worldwidewounds.com/2004/november/Thomas/Introducing-Silver-Dressings.html (accessed on 30 March 2016).

3. Silver, L.L. Multi-targeting by monotherapeutic antibacterials. Nat. Rev. Drug Discov. 2007, 6, 41-55. [CrossRef] [PubMed]

4. Schwarz, F.P.; Hauser-Gerspach, I.; Waltimo, T.; Stritzker, B. Antibacterial properties of silver containing diamond like carbon coatings produced by ion induced polymer densification. Surf. Coat. Technol. 2011, 205, 4850-4854. [CrossRef]

5. Thet, N.T.; Alves, D.R.; Bean, J.E.; Booth, S.; Nzakizwanayo, J.; Young, A.E.R.; Jones, B.V.; Jenkins, A.T.A. Prototype development of the intelligent hydrogel wound dressing and its efficacy in the detection of model pathogenic wound biofilms. ACS Appl. Mater. Interfaces 2015. [CrossRef] [PubMed]

6. Bociaga, D.; Komorowski, P.; Batory, D.; Szymanski, W.; Olejnik, A.; Jastrzebski, K.; Jakubowski, W. Silver-doped nanocomposite carbon coatings (Ag-DLC) for biomedical applications-physiochemical and biological evaluation. Appl. Surf. Sci. 2015, 355, 388-397. [CrossRef]

7. David, M.Z.; Daum, R.S. Community-associated methicillin-resistant staphylococcus aureus: Epidemiology and clinical consequences of an emerging epidemic. Clin. Microbiol. Rev. 2010, 23, 616-687. [CrossRef] [PubMed]

8. Hiramatsu, K.; Katayama, Y.; Matsuo, M.; Sasaki, T.; Morimoto, Y.; Sekiguchi, A.; Baba, T. Multi-drug-resistant staphylococcus aureus and future chemotherapy. J. Infect. Chemother. 2014, 20, 593-601. [CrossRef] [PubMed]

9. Paladini, F.; Picca, R.A.; Sportelli, M.C.; Cioffi, N.; Sannino, A.; Pollini, M. Surface chemical and biological characterization of flax fabrics modified with silver nanoparticles for biomedical applications. Mater. Sci. Eng. C Mater. Biol. Appl. 2015, 52,1-10. [CrossRef] [PubMed]

10. Owens, B. Silver makes antibiotics thousands of times more effective. Nature News, 19 June 2013. [CrossRef]

11. Knetsch, M.L.W.; Koole, L.H. New strategies in the development of antimicrobial coatings: The example of increasing usage of silver and silver nanoparticles. Polymers 2011, 3, 340-366. [CrossRef]

12. Koerner, E.; Aguirre, M.H.; Fortunato, G.; Ritter, A.; Ruehe, J.; Hegemann, D. Formation and distribution of silver nanoparticles in a functional plasma polymer matrix and related Ag+ release properties. Plasma Processes Polym. 2010, 7, 619-625. [CrossRef]

13. Quelemes, P.V.; Araruna, F.B.; de Faria, B.E.F.; Kuckelhaus, S.A.S.; da Silva, D.A.; Mendonca, R.Z.; Eiras, C.; Soares, M.J.d.S.; Leite, J.R.S.A. Development and antibacterial activity of cashew gum-based silver nanoparticles. Int. J. Mol. Sci. 2013, 14, 4969-4981. [CrossRef] [PubMed]

14. Lazic, V.; Saponjic, Z.; Vodnik, V.; Dimitrijevic, S.; Jovancic, P.; Nedeljkovic, J.; Radetic, M. A study of the antibacterial activity and stability of dyed cotton fabrics modified with different forms of silver. J. Serbian Chem. Soc. 2012, 77, 225-234. [CrossRef]

15. Palomba, M.; Carotenuto, G.; Cristino, L.; Di Grazia, M.A.; Nicolais, F.; De Nicola, S. Activity of antimicrobial silver polystyrene nanocomposites. J. Nanomater. 2012. [CrossRef]

16. Jamuna-Thevi, K.; Bakar, S.A.; Ibrahim, S.; Shahab, N.; Toff, M.R.M. Quantification of silver ion release, in vitro cytotoxicity and antibacterial properties of nanostuctured $\mathrm{Ag}$ doped $\mathrm{TiO}_{2}$ coatings on stainless steel deposited by rf magnetron sputtering. Vacuum 2011, 86, 235-241. [CrossRef] 
17. Alissawi, N.; Zaporojtchenko, V.; Strunskus, T.; Hrkac, T.; Kocabas, I.; Erkartal, B.; Chakravadhanula, V.S.K.; Kienle, L.; Grundmeier, G.; Garbe-Schoenberg, D.; et al. Tuning of the ion release properties of silver nanoparticles buried under a hydrophobic polymer barrier. J. Nanopart. Res. 2012, 14. [CrossRef]

18. Larese, F.F.; D'Agostin, F.; Crosera, M.; Adami, G.; Renzi, N.; Bovenzi, M.; Maina, G. Human skin penetration of silver nanoparticles through intact and damaged skin. Toxicology 2009, 255, 33-37. [CrossRef] [PubMed]

19. Tolaymat, T.M.; El Badawy, A.M.; Genaidy, A.; Scheckel, K.G.; Luxton, T.P.; Suidan, M. An evidence-based environmental perspective of manufactured silver nanoparticle in syntheses and applications: A systematic review and critical appraisal of peer-reviewed scientific papers. Sci. Total Environ. 2010, 408, 999-1006. [CrossRef] [PubMed]

20. Zhou, H.; Xu, L.; Ogino, A.; Nagatsu, M. Investigation into the antibacterial property of carbon films. Diam. Relat. Mater. 2008, 17, 1416-1419. [CrossRef]

21. Silver as an Anti-Bacterial. Available online: https://www.silverinstitute.org/site/silver-in-technology/ silver-in-medicine/bandages / (accessed on 30 March 2016).

22. Elastoplast-Antibacterial Waterproof. Available online: http://www.en.elastoplast.ca/Products/waterproofantibacterial (accessed on 30 March 2016).

23. Band-aid Plus Antibiotic Adhesive Bandages, Assorted Sizes. Available online: http://www.drugstore.com/ band-aid-plus-antibiotic-adhesive-bandages-assorted-sizes/qxp149702 (accessed on 30 March 2016).

24. Percival, S.L.; Bowler, P.G.; Dolman, J. Antimicrobial activity of silver-containing dressings on wound microorganisms using an in vitro biofilm model. Int. Wound J. 2007, 4, 186-191. [CrossRef] [PubMed]

25. Newman, G.R.; Walker, M.; Hobot, J.A.; Bowler, P.G. Visualisation of bacterial sequestration and bactericidal activity within hydrating hydrofiber ${ }^{\circledR}$ wound dressings. Biomaterials 2006, 27, 1129-1139. [CrossRef] [PubMed]

26. Wach, R.A.; Mitomo, H.; Nagasawa, N.; Yoshii, F. Radiation crosslinking of carboxymethylcellulose of various degree of substitution at high concentration in aqueous solutions of natural pH. Radiat. Phys. Chem. 2003, 68, 771-779. [CrossRef]

27. Meskinis, S.; Vasiliauskas, A.; Slapikas, K.; Gudaitis, R.; Andrulevicius, M.; Ciegis, A.; Niaura, G.; Kondrotas, R.; Tamulevicius, S. Bias effects on structure and piezoresistive properties of DLC:Ag thin films. Surf. Coat. Technol. 2014, 255, 84-89. [CrossRef]

28. Choi, H.W.; Dauskardt, R.H.; Lee, S.-C.; Lee, K.-R.; Oh, K.H. Characteristic of silver doped DLC films on surface properties and protein adsorption. Diam. Relat. Mater. 2008, 17, 252-257. [CrossRef]

29. Yaremchuk, I.; Meskinis, S.; Fitio, V.; Bobitski, Y.; Slapikas, K.; Ciegis, A.; Balevicius, Z.; Selskis, A.; Tamulevicius, S. Spectroellipsometric characterization and modeling of plasmonic diamond-like carbon nanocomposite films with embedded ag nanoparticles. Nanoscale Res. Lett. 2015, 10. [CrossRef] [PubMed]

30. Meškinis, Š.; Vasiliauskas, A.; Šlapikas, K.; Gudaitis, R.; Yaremchuk, I.; Fitio, V.; Bobitski, Y.; Tamulevičius, S. Annealing effects on structure and optical properties of diamond-like carbon films containing silver. Nanoscale Res. Lett. 2016, 11, 1-9. [CrossRef] [PubMed]

31. Tsougeni, K.; Vourdas, N.; Tserepi, A.; Gogolides, E.; Cardinaud, C. Mechanisms of oxygen plasma nanotexturing of organic polymer surfaces: From stable super hydrophilic to super hydrophobic surfaces. Langmuir 2009, 25, 11748-11759. [CrossRef] [PubMed]

32. Hesse, E.; Creighton, J.A. Investigation by surface-enhanced raman spectroscopy of the effect of oxygen and hydrogen plasmas on adsorbate-covered gold and silver island films. Langmuir 1999, 15, 3545-3550. [CrossRef]

33. Tamulevicius, T.; Tamuleviciene, A.; Virganavicius, D.; Vasiliauskas, A.; Kopustinskas, V.; Meskinis, S.; Tamulevicius, S. Structuring of DLC:Ag nanocomposite thin films employing plasma chemical etching and ion sputtering. Nucl. Instrum. Methods Phys. Res. Sect. B-Beam Interact. Mater. Atoms 2014, 341, 1-6. [CrossRef]

34. Zeng, Y.X.; Chen, L.H.; Zou, Y.L.; Nguyen, P.A.; Hansen, J.D.; Alford, T.L. Processing and encapsulation of silver patterns by using reactive ion etch and ammonia anneal. Mater. Chem. Phys. 2000, 66, 77-82. [CrossRef]

35. Nguyen, P.; Zeng, Y.X.; Alford, T.L. Reactive ion etch of patterned and blanket silver thin films in $\mathrm{Cl}^{-2} / \mathrm{O}^{-2}$ and $\mathrm{O}^{-2}$ glow discharges. J. Vac. Sci. Technol. B 1999, 17, 2204-2209. [CrossRef]

36. Marciano, F.R.; Bonetti, L.F.; Da-Silva, N.S.; Corat, E.J.; Trava-Airoldi, V.J. Wettability and antibacterial activity of modified diamond-like carbon films. Appl. Surf. Sci. 2009, 255, 8377-8382. [CrossRef] 
37. Cao, H.; Qiao, Y.; Liu, X.; Lu, T.; Cui, T.; Meng, F.; Chu, P.K. Electron storage mediated dark antibacterial action of bound silver nanoparticles: Smaller is not always better. Acta Biomater. 2013, 9, 5100-5110. [CrossRef] [PubMed]

38. Liu, H.-L.; Dai, S.A.; Fu, K.-Y.; Hsu, S.-H. Antibacterial properties of silver nanoparticles in three different sizes and their nanocomposites with a new waterborne polyurethane. Int. J. Nanomed. 2010, 5, 1017-1028.

39. Ip, M.; Lui, S.L.; Poon, V.K.M.; Lung, I.; Burd, A. Antimicrobial activities of silver dressings: An in vitro comparison. J. Med. Microbiol. 2006, 55, 59-63. [CrossRef] [PubMed]

40. Wright, J.B.; Lam, K.; Burrell, R.E. Wound management in an era of increasing bacterial antibiotic resistance: A role for topical silver treatment. Am. J. Infect. Control 1998, 26, 572-577. [CrossRef] [PubMed]

41. Edwards, R.; Harding, K.G. Bacteria and wound healing. Curr. Opin. Infect. Dis. 2004, 17, 91-96. [CrossRef] [PubMed]

42. Vimala, K.; Yallapu, M.M.; Varaprasad, K.; Reddy, N.N.; Ravindra, S.; Naidu, N.S.; Raju, K.M. Fabrication of curcumin encapsulated chitosan-PVA silver nanocomposite films for improved antimicrobial activity. J. Biomater. Nanobiotechnol. 2011, 2, 55-64. [CrossRef]

43. Yilma, A.N.; Singh, S.R.; Dixit, S.; Dennis, V.A. Anti-inflammatory effects of silver-polyvinyl pyrrolidone (Ag-PVP) nanoparticles in mouse macrophages infected with live chlamydia trachomatis. Int. J. Nanomed. 2013, 8, 2421-2432.

44. Meskinis, S.; Vasiliauskas, A.; Slapikas, K.; Niaura, G.; Juskenas, R.; Andrulevicius, M.; Tamulevicius, S. Structure of the silver containing diamond like carbon films: Study by multiwavelength raman spectroscopy and xrd. Diam. Relat. Mater. 2013, 40, 32-37. [CrossRef]

45. Yaremchuk, I.; Tamuleviciene, A.; Tamulevicius, T.; Slapikas, K.; Balevicius, Z.; Tamulevicius, S. Modeling of the plasmonic properties of DLC-Ag nanocomposite films. Phy. Status Solidi A-Appl. Mater. Sci. 2014, 211, 329-335. [CrossRef]

46. Meškinis, Š.; Tamulevičius, T.; Niaura, G.; Šlapikas, K.; Vasiliauskas, A.; Ulčinas, O.; Tamulevičius, S. Surface enhanced raman scattering effect in diamond like carbon films containing ag nanoparticles. J. Nanosci. Nanotechnol. 2016, 16, 1-9.

47. Seil, J.T.; Webster, T.J. Antimicrobial applications of nanotechnology: Methods and literature. Int. J. Nanomed. $2012,7,2767-2781$

(C) 2016 by the authors; licensee MDPI, Basel, Switzerland. This article is an open access article distributed under the terms and conditions of the Creative Commons Attribution (CC-BY) license (http://creativecommons.org/licenses/by/4.0/). 